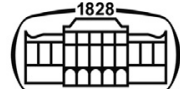

AKADÉMIAI KIADÓ

Journal of Behavioral

Addictions

10 (2021) 2, 253-262

DOI:

$10.1556 / 2006.2021 .00028$

(c) 2021 The Author(s)

\section{FULL-LENGTH REPORT}

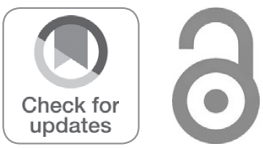

\title{
Problematic Internet use among residential college students during the COVID-19 lockdown: A social network analysis approach
}

\author{
YIWEI XIA ${ }^{1}$, YANYING FAN ${ }^{1}$, TZU-HSUAN LIU ${ }^{2}$ and \\ ZHIHAO $\mathrm{MA}^{3 *}$ (1)
}

\author{
${ }^{1}$ School of Law, Southwestern University of Finance and Economics, Chengdu 611130, China \\ ${ }^{2}$ School of Political Science and Public Administration, Huaqiao University, Quanzhou 362021, \\ China \\ ${ }^{3}$ Computational Communication Collaboratory, School of Journalism and Communication, \\ Nanjing University, Nanjing 210023, China
}

Received: February 19, 2021 • Revised manuscript received: April 6, 2021 • Accepted: April 27, 2021

Published online: May 20, 2021

\begin{abstract}
Background and aims: During the COVID-19 lockdown, problematic Internet use (PIU) has become a serious issue among residential college students, who remain physically isolated from off-campus society. This study constructs an integrated model to investigate the influencing mechanisms of internal locus of control (LOC) and objective peer effects. Methods: Residential college students $(n=494)$ were surveyed from a single department of a Chinese university. An item from the World Value Survey was employed to measure internal LOC, while objective peer effects were assessed via friends' mutual nominations. Finally, PIU was measured using Young's Internet Addiction Tests, while a social network analysis and logit regression were combined to estimate various factors' effects on PIU. Results: In our sample, the prevalence rate of PIU was $30.6 \%$, and while internal LOC was a protective factor for PIU, its protective role was diluted when exposed to a peer environment with high PIU prevalence. Furthermore, indegree performed contrasting roles on PIU under various network conditions. It acted as a protective factor when exposed to a low prevalence of PIU in a peer environment; however, it became a risk factor when PIU peers were prevalent. Lastly, the protective efficacy of betweenness was activated when individuals had more than one PIU friend. Discussion and conclusions: Further intervention studies focusing on individuals with a weak internal LOC are recommended during the lockdown. Additionally, interventions that consider the network structures carefully, may enhance the prevention of PIU.
\end{abstract}

\section{KEYWORDS}

problematic Internet use, residential college students, internal locus of control, objective peer effects, COVID-19, social network analysis

\section{INTRODUCTION}

The current COVID-19 pandemic has hugely impacted national administrations and the daily life of individuals in almost every country and region in the world. Governments have implemented lockdown measures on a worldwide scale to reduce its rapid spread by promoting the concept of social distance between individuals (Alfano \& Ercolano, 2020; Di Domenico, Pullano, Sabbatini, Boëlle, \& Colizza, 2020; Lau et al., 2020). Optimistic appraisals about the direct effects of lockdown measures in terms of coping with public health emergencies have dominated public health literature (Alfano \& Ercolano, 2020). However, potential mental health consequences and problematic behaviors due to the resulting isolation are arousing the attention of scholars (Pfefferbaum \& North, 2020). The sharp reduction and considerable changes in daily offline activities and routines, respectively, due to COVID-19, 
may enhance the role of online behaviors in people's daily life, consequently instigating problematic media use (Ko \& Yen, 2020; Mestre-Bach, Blycker, \& Potenza, 2020; Sinclair et al., 2020) and problematic internet use (PIU) (Dong, Yang, Lu, \& Hao, 2020; Siste et al., 2020).

PIU is more prevalent among college students than among general Internet users (Young, Yue, \& Ying, 2012). COVID-19 lockdown measures require universities to shut down their campus facilities and conduct all academic activities online, making college students more vulnerable to PIU. Previous studies revealed that PIU has several risk factors amidst a lockdown. Surveyed American college students seven days after the lockdown, Flaudias et al. (2020) suggested that stressors triggered by the lockdown and media exposure regarding COVID-19 were associated with problematic eating behaviors. Furthermore, an online survey conducted by Odriozola-González, Planchuelo-Gómez, Jesús Irurtia, and Luis-Garcia (2020) reported that over a quarter of the university members experienced moderate to extreme depression and stress, two weeks after the lockdown was implemented. Another study found that the mental status of Swiss college students worsened during the lockdown than before it was implemented (Elmer, Mepham, and Stadtfeld, 2020).

However, despite the existing literature exploring the psychiatric burdens of lockdown, few studies have focused on its effects on PIU, particularly among residential college students, who have majorly been isolated on a closed campus. These students are at a higher risk of PIU, since the Internet is their only efficient way to access the outside world (Arnett, Žukauskiene, and Sugimura, 2014). Anderson, Steen, and Stavropoulos (2017) concluded that previous studies investigating the risk and protective factors of PIU among adolescents and emerging adults, have primarily focused on individual (e.g., emotional regulation, personality traits, and mental status) and contextual factors (e.g., parenting, friendship quality, and classroom environment). Thus, to develop a better understanding of PIU among residential college students during COVID-19 lockdown, we employed the internal locus of control and objective peer effects as the individual and contextual influencing factors, respectively.

\section{Internal locus of control and PIU}

Rotter (1966) proposed that a locus of control (LOC) is an essential personality trait ingredient that describes an individual's perception of their capacity to control their life events. The theory divided the LOC into two parts: internal and external. Individuals with strong internal loci of control tend to conceive events' outcomes as being controlled by their actions, whereas individuals with strong external loci of control usually believe that the outcome of events involves the intervention of others (Rotter, 1966). Both theoretical taxonomies have been widely adopted by empirical research and reveal similar results. Studies have suggested that an internal LOC contributes to one's subjective wellbeing (Landau, 1995; Spector et al., 2001) and plays a protective role in terms of coping with daily stress (Helmbrecht \& Ayars, 2021; Xia \& Ma, 2020). In addition, an external LOC triggers poor mental health (Kurtović, Vuković, \& Gajić, 2018; Sullivan, Thompson, Kounali, Lewis, \& Zammit, 2017) and problematic, or even deviant behaviors (Blanchard \& Henle, 2008; Pals, Love, Hannibal, \& Waren, 2016).

In PIU studies, scholars assume that individuals with weak internal loci of control or strong external loci of control usually offer minimal effort when it comes to earning rewards in real life and have a high likelihood of devoting themselves to the virtual world (Koo, 2009; Lloyd, Frost, Kuliesius, \& Jones, 2019). Empirical evidence also supported this assumption, like Rotsztein (2003), who revealed a positive relationship between an external LOC and PIU among college students. Additionally, Hair and colleagues (2007) revealed that stressed email usage is statistically significantly related to external LOC. Chak and Leung (2004) adopted Levenson's (1973) taxonomy dimensions and found that an internal local of control decreases the likelihood of PIU. Recently, Lloyd et al. (2019) extended the LOC theory to the virtual world in an online gaming study; moreover, they classified the LOC further into two categories-in real life and in a game. Results indicated that both an external LOC in real life and internal LOC in a game environment triggered problematic gaming.

\section{Objective peer effects on PIU}

The role of peers in understanding PIU is another important focus of recent studies (Li et al., 2013; Soh, Chew, Koay, \& Ang, 2018). Social capital theory (Kawachi \& Berkman, 2014), complex contagion theory (Centola \& Macy, 2007), and social bond theory (Hirschi, 1969) suggest that prosocial and antisocial behaviors could be diffused through a peer network. Empirical evidence demonstrated that misconduct is more contagious during adolescence than childhood and emerging adulthood (Daw, Margolis, \& Verdery, 2015; Lorant \& Tranmer, 2019), whereas prosocial conduct or nondeviant behaviors are less contagious (Rulison, Kreager, \& Wayne Osgood, 2014). Moffitt (1993) described this as the gap between one's biological and social maturity. During adolescence, individuals tend to mimic misconduct from peers to obtain desirable resources. When biological and social maturities are balanced during emerging adulthood, the transmissibility of misconduct decreases.

To substantiate Moffitt's (1993) theory, studies have adopted both subjective and objective measures of peer effects, which revealed inconsistent findings. A recent narrative review (Hoeben, Meldrum, Walker, \& Young, 2016) suggested that future studies should use a social network analysis (SNA) to measure objective peer effects, while avoiding measurement bias (e.g., assumed similarity bias and samesource bias) caused by subjective measures. However, recent antisocial behavior and health studies using SNA mostly focus on adolescents (Haynie, 2002; Lorant \& Tranmer, 2019), and college student populations remain largely underexplored (Hoeben et al., 2016). Additionally, studies attributing PIU to peer effects seldom employ SNA. Thus, to address this methodological limitation, we applied SNA to measure the residential college students' objective peer effects. 
Three indicators were generated from SNA in our study: indegree, betweenness, and the percentage of PIU peers.

Indegree and betweenness are basic network attributes that portray an individual's social position. Indegree typically refers to an individual's popularity (Faris, Felmlee, \& McMillan, 2020; Haynie, 2001) or peer acceptance (Rulison et al., 2014). Researchers suggested that indegree is a useful indicator to capture an individual's integration capacity attributes (Baron \& Tindall, 1993). Studies also revealed that individuals with high indegree usually display stronger influence in disseminating information or social values among people adhering to similar norms (Choi, Hecht, \& Smith, 2017; Huang \& Sun, 2014). On the other hand, betweenness describes the bridging potential within a community (Rulison et al., 2014), and can be used to measure one's social status (Faris \& Felmlee, 2011, 2014; Foshee et al., 2013, 2016). It represents individuals' control capacities in a broader scope. Individuals with high betweenness may not necessarily share homogeneous attributes with other network members, but they may demonstrate an ability to link diverse sub-communities within the network.

Further, the percentage of PIU peers is the key element that describes peers' PIU status. In an SNA approach, several studies indicated that the status of one's friends in a selfselected network may also change the status of their network (Haynie, 2001, 2002; Lee \& Lee, 2020). For example, Haynie (2002) revealed that the percentage of delinquent friends in one's network is a risk factor of personal subsequent delinquency. Lee and Lee (2020) reported that depression is mostly contagious by both median and high depressive peers within one's friend network. In addition, Haynie (2001) revealed connections between indicators of a peer network and individual deviant behaviors that were strengthened by deviant friends in a self-selected network. These results implied that the percentage of PIU peers among a residential college student's self-selected network may serve as both a trigger of personal PIU risk as well as a catalyst between influencing factors (internal LOC, indegree, and betweenness) and PIU risk.

\section{Current study overview}

In the current study, residential college students living in closed universities reduced their participation in offline conveniences during the COVID-19 lockdown. Since offline community activities were restricted to university members, the Internet provided a vent for students to access activities outside of the university, amplifying the risk of suffering from PIU. Thus, preventing PIU is a burning issue during these kinds of emergency measures. To provide a better understanding of PIU antecedents, we employed the notion of an internal LOC and adopted the friend nomination method to construct college students' objective peer effects in order to answer the following: (1) Does an internal LOC serve as a protective factor for PIU? (2) Are objective peer effects (indegree, betweenness, and percentage of PIU peers) associated with PIU? (3) Does the percentage of PIU peers moderate the associations between influencing factors (internal LOC, indegree, and betweenness) and PIU, and if so, how?

\section{METHODS}

\section{Participants}

Participants were students recruited from a large university in a major metropolitan area in China; this university adopted a closed-management strategy at the beginning of the semester (from July 1, 2020 to September 1, 2020) to halt the spread of the pandemic. Therefore, students from one class of a department, which strictly adhered to this strategy, were selected. For sociodemographic information, we included sex (female $=1$, male $=0)$, age, and ethnicity $(1=$ Han, $0=$ other).

\section{Measures}

The Chinese version of Young's Internet Addiction Tests (IAT) (Young, 1998) was adopted to screen individuals' PIU, and it contains eight dichotomized items, representing eight distinct symptoms of PIU. The IAT has an adequate reliability (Cronbach's alpha $=0.754$ ) in the current sample. Participants were required to report their perceptions of each question during the lockdown, and if they answered "yes" to at least five of the eight criteria, they were classified as experiencing PIU (Young, 1998).

Internal LOC was evaluated by asking participants the following question from the World Value Survey (Inglehart et al., 2014) in the context of the university lockdown: "Some people feel that they have free choice and control over their lives, while others feel that what they do has no real effect on what happens to them." The response scores ranged from one to ten, where a higher score represented a greater sense of control.

Indegree was calculated based on the number of friendship nominations received from others. A higher score meant that the participants received more friendship nominations (i.e., they are more popular) than those with lower indegree scores. On the other hand, betweenness was assessed by computing the percentage of the shortest paths that pass through specific individuals (Burt, 2015). Thus, a higher betweenness score indicated that the individual was more likely to function in a "bridge spanning" role across the entire peer friendship network. Lastly, the percentage of PIU peers was calculated by computing the proportion of the respondents' peers, who satisfied the PIU criteria (IAT scores $\geq 5$ ). In this study, we operationalized a personal peer network via mutually nominated friends. For example, in a hypothetical network, if $\mathrm{A}$ nominated $\mathrm{B}, \mathrm{C}$, and $\mathrm{D}$ as their friends, but only $\mathrm{B}$ and $\mathrm{C}$ nominated $\mathrm{A}$ in return, then only $\mathrm{B}$ and $\mathrm{C}$ were considered as A's peer network.

\section{Procedure}

An online survey was conducted with 546 undergraduate students from a class of a single university department and 
data were collected from October 8-30, 2020. The participation rate was $96.3 \%$, and missing data was largely due to absences. During the survey, participants were required to nominate five (maximum) best friends (average $=4.88$ ) from the same department. Since every student in the department was invited to participate, the mutual nomination system was believed to capture the friendship network structure of the whole department. The networkrelated variables were constructed based on the collected friendship network. Individuals who did not receive any friendship nominations were removed from the analysis because their network-related variables could not be calculated. Finally, 494 individuals were included in the study's analysis.

\section{Statistical analysis}

A sequence of statistical procedures was applied to explore the research questions. Descriptive statistics were computed initially for all the study variables to outline the sample characteristics. Further, t-tests were performed to examine the differences between the PIU and non-PIU samples. Network graphs were constructed to display individuals' distribution across the peer network. The nodes' layout was constructed based on the Fruchterman-Reingold layout algorithm (Fruchterman \& Reingold, 1991). The size of the node in the network graphs were weighted in accordance with the internal LOC, indegree, and betweenness, respectively. Logit regressions with interaction terms were estimated to investigate whether the internal LOC, objective peer effects, and their interaction items were statistically significantly associated with PIU. Afterward, simple slope tests (Dawson, 2014) and a Shapley value decomposition (Shorrocks, 1982) were conducted to further investigate the existence of moderating effects and their relative contribution to the regression model.

\section{Ethics}

Written informed consent was obtained from all participants prior to the interviews and survey administration. The current study was approved by the research ethics committee of School of Political Science and Public Administration at Huaqiao University.

\section{RESULTS}

Table 1 presents the descriptive statistics and t-test results between non-PIU and PIU students for all the variables analyzed in the current study. The results indicate that $30.6 \%$ of the sample suffered from PIU. Of these, $71.5 \%$ were females, $87.3 \%$ who were Han, and the mean age was 19.69 years. No sociodemographic variables presented statistical differences between non-PIU and PIU students. Moreover, indegree and the percentage of PIU peers were also equally distributed between these groups. However, compared to non-PIU students, the PIU students reported statistically significant lower levels for both an internal LOC and betweenness.

Figure 1 presents the egocentric friendship network for each participant in the current study. Figure la suggests that the non-PIU students had a stronger internal LOC, as compared to the PIU students. These results were consistent with the T-test results shown in Table 1. Further, Fig. 1b shows that the relationship between indegree and the probability of PIU was complex. Some parts of Fig. 1b (e.g. the upper and right parts), suggest that students with higher indegree had lower probabilities of PIU, but other parts show the reverse. For example, Part I (see Fig. 1d) suggests a negative association between indegree and the probability of PIU. Meanwhile, Fig. 1c reveals that the students with high betweenness usually had a low likelihood of PIU. When comparing Figs $1 \mathrm{~b}$ and $1 \mathrm{c}$, it is easy to observe that participants with a high indegree did not necessarily have a high betweenness within the network. When comparing the same parts of two sub-figures among six participants who had relatively low indegree, as shown in Fig. 1e (Part II in Fig. 1b), five nodes had statistically significant high betweenness, as demonstrated in Fig. If (Part III in Fig. 1c). These results indicate that difference between the roles of indegree and betweenness were statistically significant in terms of triggering PIU.

Table 2 shows the results of logit regression and Shapley value decomposition for the variables' main and moderating effects. In Column 1 , the internal LOC was negatively associated with the probability of PIU ( $\beta=$ $-0.194, P<0.001)$, indicating that it was a protective factor of PIU risk among residential college students.

Table 1. Descriptive statistics $(n=494)$

\begin{tabular}{lccccrr}
\hline Variables & Mean (SD) & $n(\%)$ & non-PIU students & PIU students & Differences & $T$ value \\
\hline PIU $(1=$ yes) & - & $151(30.6 \%)$ & - & - & - & - \\
Female $(1=$ yes $)$ & - & $353(71.5 \%)$ & 0.723 & 0.695 & 0.028 & 0.626 \\
Age (years) & $19.690(1.327)$ & - & 19.638 & 19.808 & -0.169 & -1.309 \\
Ethnicity (1 = Han) & - & $431(87.3 \%)$ & 0.872 & 0.874 & -0.002 & -0.075 \\
Internal locus of control & $6.692(1.722)$ & - & 6.860 & 6.311 & 0.549 & $3.297^{* * *}$ \\
Indegree & $4.067(1.934)$ & - & 4.172 & 3.828 & 0.344 & 1.826 \\
Betweenness & $0.010(0.014)$ & - & 0.011 & 0.008 & 0.003 & $2.398^{*}$ \\
Percentage of PIU peers & $0.283(0.295)$ & - & 0.288 & 0.272 & 0.016 & 0.553 \\
\hline
\end{tabular}

Note: PIU refers to problematic Internet use. Numbers in columns "non-PIU students" and "PIU students" are mathematical means of variables for non-PIU students $(n=343)$ and PIU students $(n=151)$, respectively. Numbers in column "Differences" are means differences between two groups of students. ${ }^{* * *} P<0.001$, ${ }^{* *} P<0.01$, ${ }^{*} P<0.05$. 
(a) Node size weighted by internal locus of control

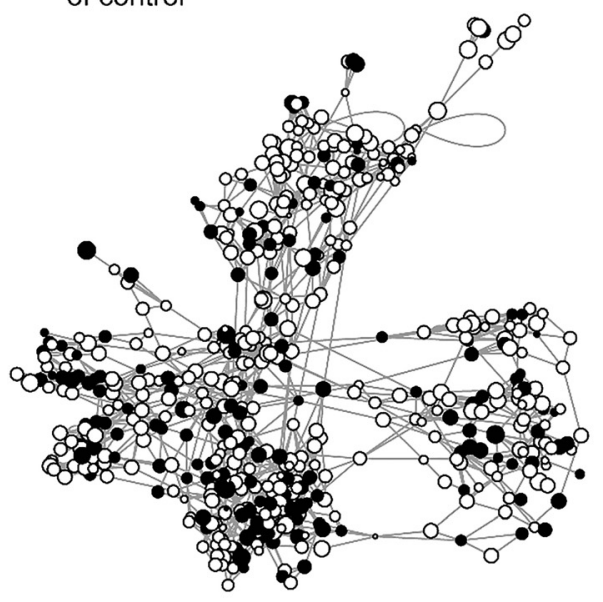

(c) Node size weighted by betweenness

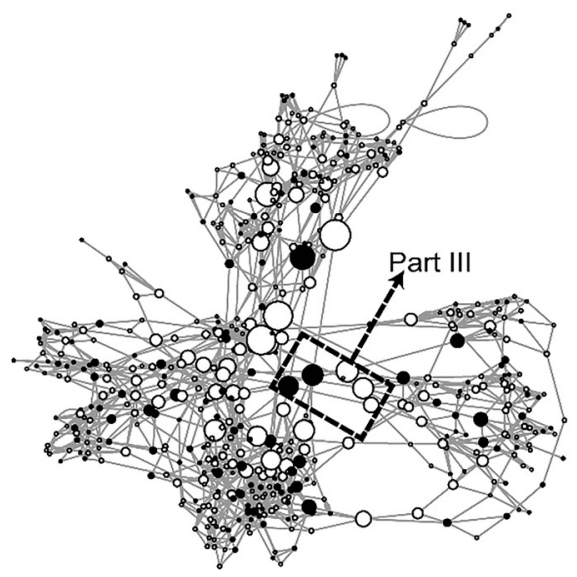

(e) Details for part ii of Fig. 1b

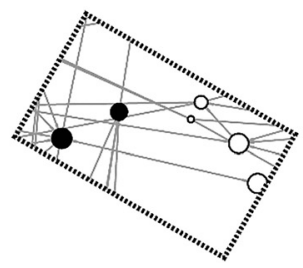

(b) Node size weighted by indegree

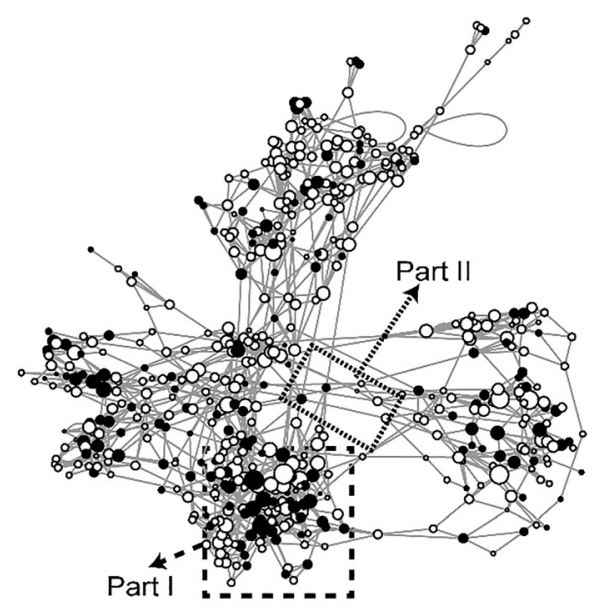

(d) Details for part i of Fig. 1b

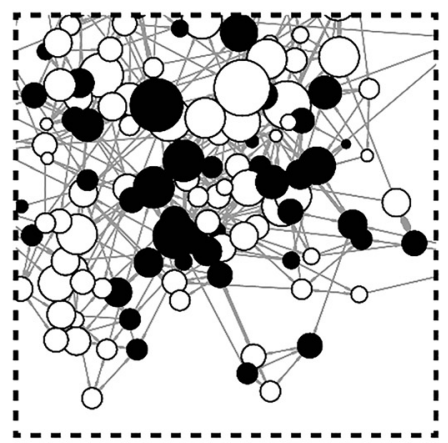

(f) Details for part iii of Fig. 1c

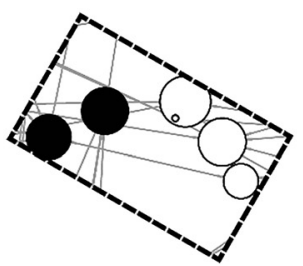

Fig. 1. Network graphs for residential college students. The node represents individuals, the edges indicate friendship nominations, the nodes' color denotes PIU status (black = with PIU, white = without PIU), and nodes' sizes in Figs 1a, b, and $c$ represent the value of the locus of control, indegree, and betweenness, respectively. PIU refers to problematic Internet use

Moreover, students with high betweenness reported a low probability of PIU ( $\beta=-18.737, P<0.05)$, whereas the indegree and percentage of PIU peers were not statistically significantly associated with the likelihood of PIU. Column 2 presents each factor's contribution rates according to the probability of PIU. Among all the independent variables, an internal LOC contributed the most (52.5\%), while betweenness was the second most important contributing factor $(26.0 \%)$.
In Column 3 of Table 2, the interaction test reveals that the percentage of PIU peers weakened the protective effects of the internal LOC $(\beta=0.543, P<0.05)$ and indegree $(\beta=$ $0.562, P<0.01)$. All three interaction items accounted for $27.7 \%$ of the contribution to the probability of PIU. Despite the interaction item of betweenness and the percentage of PIU peers not being statistically significant $(\beta=-72.385$, $P>0.05)$, it held the maximum proportion among the three interaction items. Thus, we further analyzed this item via a 
Table 2. Logit regression and Shapley value decomposition results

\begin{tabular}{|c|c|c|c|c|}
\hline & (1) & (2) & (3) & (3) \\
\hline Female $(1=$ yes $)$ & $\begin{array}{r}-0.189 \\
(0.223)\end{array}$ & $2.7 \%$ & $\begin{array}{r}-0.196 \\
(0.227)\end{array}$ & $1.8 \%$ \\
\hline Age (years) & $\begin{array}{c}0.099 \\
(0.076)\end{array}$ & $7.9 \%$ & $\begin{array}{l}0.09 \\
(0.078)\end{array}$ & $4.5 \%$ \\
\hline Ethnicity (1 = Han) & $\begin{array}{c}0.041 \\
(0.304)\end{array}$ & $0.1 \%$ & $\begin{array}{c}-0.058 \\
(0.31)\end{array}$ & $0.1 \%$ \\
\hline $\begin{array}{l}\text { Internal locus of } \\
\text { control }\end{array}$ & $\begin{array}{l}-0.194^{* * *} \\
(0.059)\end{array}$ & $52.5 \%$ & $\begin{array}{l}-0.349^{* * * *} \\
(0.087)\end{array}$ & $37.4 \%$ \\
\hline Indegree & $\begin{array}{c}-0.034 \\
(0.06)\end{array}$ & $8.8 \%$ & $\begin{array}{r}-0.184^{*} \\
(0.088)\end{array}$ & $8.9 \%$ \\
\hline Betweenness & $\begin{array}{r}-18.737^{*} \\
(9.442)\end{array}$ & $26.0 \%$ & $\begin{array}{l}-3.407 \\
(11.204)\end{array}$ & $9.6 \%$ \\
\hline $\begin{array}{l}\text { Percentage of PIU } \\
\text { peers }\end{array}$ & $\begin{array}{r}-0.246 \\
(0.345)\end{array}$ & $2.0 \%$ & $\begin{array}{l}-5.331^{* * *} \\
(1.736)\end{array}$ & $10.1 \%$ \\
\hline $\begin{array}{l}\text { Internal locus of } \\
\text { control } \times \\
\text { Percentage of } \\
\text { PIU peers }\end{array}$ & & & $\begin{array}{c}0.543^{*} \\
(0.220)\end{array}$ & $7.3 \%$ \\
\hline $\begin{array}{l}\text { Indegree } \times \\
\text { Percentage of } \\
\text { PIU peers }\end{array}$ & & & $\begin{array}{l}0.562^{* *} \\
(0.212)\end{array}$ & $8.5 \%$ \\
\hline $\begin{array}{l}\text { Betweenness } \times \\
\text { Percentage of } \\
\text { PIU peers }\end{array}$ & & & $\begin{array}{r}-72.385 \\
(40.485)\end{array}$ & $11.9 \%$ \\
\hline Constant & $\begin{array}{r}-1.004 \\
(1.596)\end{array}$ & & $\begin{array}{c}0.647 \\
(1.699)\end{array}$ & \\
\hline Observations & 494 & & 494 & \\
\hline Pseudo $R^{2}$ & 0.034 & & 0.057 & \\
\hline Log likelihood & -293.669 & & -286.674 & \\
\hline $\mathrm{Chi}^{2}$ & 20.865 & & 34.855 & \\
\hline
\end{tabular}

Note: PIU refers to problematic internet use. Numbers in columns (2) and (4) are contribution rates of different factors to the probability of PIU for models at column (1) and (3), respectively. Standard errors are in parentheses. ${ }^{* * *} P<0.001,{ }^{* *} P<0.01$, ${ }^{*} P<0.05$.

simple slope test. While Fig. 2 shows the effects of the internal LOC, indegree, and betweenness on the probability of PIU by different percentages of PIU peers, the results of the slope tests are shown in Table 3.

First, Fig. 2a demonstrates that the negative relationship between an internal LOC and the probability of PIU was weakened with an increased percentage of PIU peers. Specifically, when the percentage of PIU peers was below or equal to $25 \%$, the internal LOC reduced the likelihood of PIU. However, this protective effect was diluted when students had a moderate to high percentage of PIU peers. Second, the role of indegree on the probability of PIU was also moderated by the percentage of PIU peers. Fig. $2 b$ reveals that the effect of indegree on the probability of PIU was reversed with an increased percentage of PIU peers. Only with an extremely low percentage of PIU peers (e.g., $0 \%$, as shown in Table 3), indegree had a protective effect on PIU; whereas, within a high percentage of a PIU peer network (e.g., $75 \%$ and $100 \%$ PIU peers, as shown in Table 3), indegree was a risk factor of PIU. Third, Fig. $2 c$ shows that the protective role of betweenness on PIU was triggered (a) Moderation role of the percentage of PIU peers on the relationship between internal locus of control and PIU

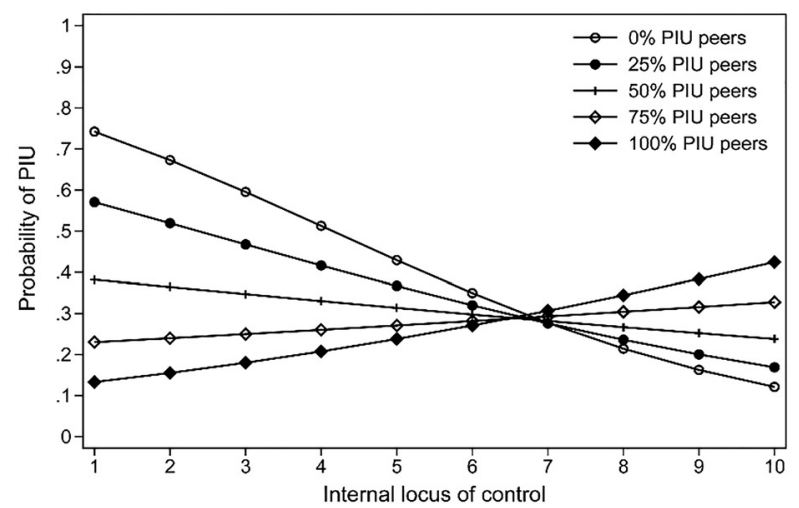

(b) Moderation role of the percentage of PIU peers on the relationship between indegree and PIU

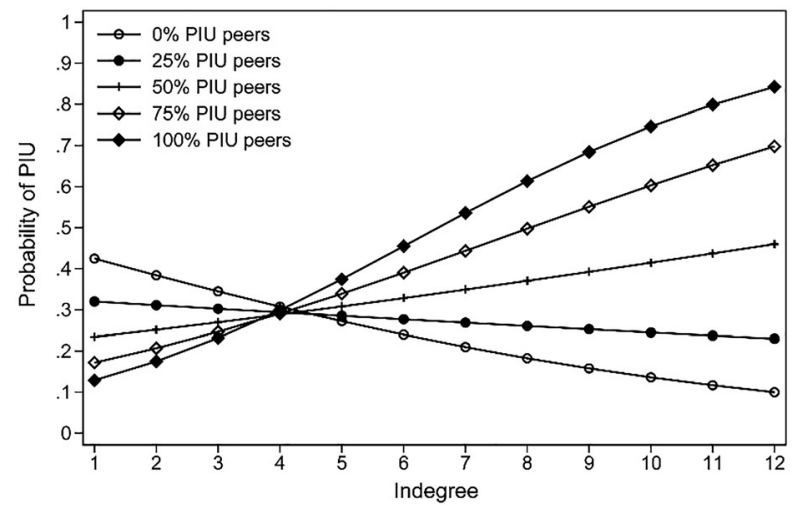

(c) Moderation role of the percentage of PIU peers on the relationship between betweenness and PIU

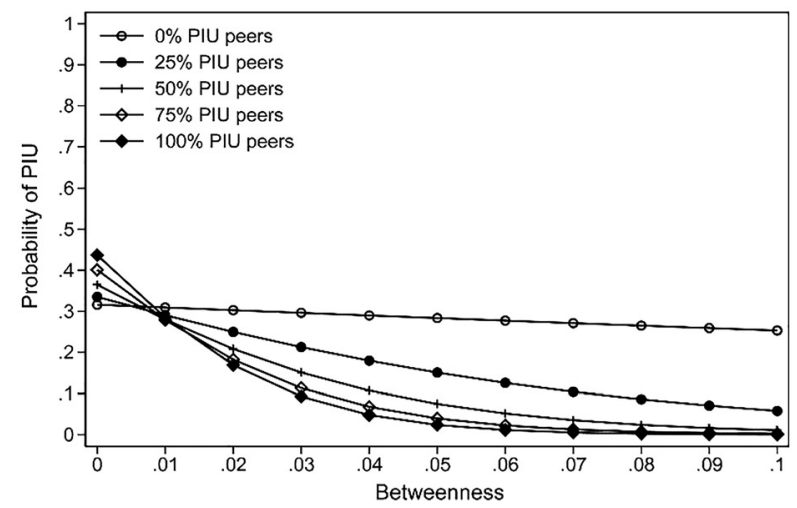

Fig. 2. Effects of internal locus of control, indegree, and betweenness on probability of PIU by different percentage of PIU peers. PIU refers to problematic Internet use

when the self-selection network had PIU peers. If the number of PIU peers in a self-selection network was zero, this protective role was inactive $(\beta=-0.658, P>0.05)$.

\section{DISCUSSION}

This study contributes to previous research on the influencing mechanisms of PIU under the COVID-19 lockdown measures. To the best of our knowledge, it is also the first to 
Table 3. Simple slope test of the effects of locus of control, indegree, and betweenness on the probability of PIU by different percentage of PIU peers

\begin{tabular}{lccc}
\hline & $\begin{array}{c}\text { Internal locus of } \\
\text { control }\end{array}$ & Indegree & Betweenness \\
\hline 0\% PIU peers & $-0.068^{* * *}$ & $-0.035^{*}$ & -0.658 \\
& $(0.015)$ & $(0.016)$ & $(2.168)$ \\
25\% PIU peers & $-0.042^{* * *}$ & -0.009 & $-4.256^{*}$ \\
& $(0.012)$ & $(0.012)$ & $(2.015)$ \\
50\% PIU peers & -0.015 & 0.019 & $-7.842^{*}$ \\
& $(0.015)$ & $(0.015)$ & $(3.234)$ \\
75\% PIU peers & 0.011 & $0.046^{*}$ & $-11.154^{*}$ \\
& $(0.023)$ & $(0.021)$ & $(4.759)$ \\
100\% PIU & 0.036 & $0.070^{*}$ & $-13.972^{*}$ \\
peers & $(0.031)$ & $(0.028)$ & $(6.118)$ \\
\hline
\end{tabular}

Note: PIU refers to problematic Internet use. Standard errors are in parentheses. ${ }^{* * *} P<0.001,{ }^{* *} P<0.01,{ }^{*} P<0.05$.

explore the factors that trigger or prohibit PIU among residential college students during a university lockdown. This is also one of the earliest studies to adopt the SNA in order to analyze whether and how PIU was diffused within a selfselection friendship network among emerging adults.

This study reveals several significant findings: (1) internal LOC and betweenness are protective factors for PIU, (2) percentage of PIU peers weakened the protective role of internal LOC on PIU, (3) indegree works as a protective factor for PIU when the percentage of PIU peers is low, whereas its risk in instigating PIU was triggered when the percentage of PIU was high, and (4) the protective role of betweenness on PIU was activated once an individual had at least one PIU peer in their friendship network.

Consistent with the majority of previous literature on the relationship between an LOC and PIU (Hair, Renaud, \& Ramsay, 2007; Koo, 2009; Rotsztein, 2003), this study reveals that residential college students with stronger internal loci of control report a lower probability of PIU. However, since an external LOC facilitates the immersion of an online virtual environment (Koo, 2009; Lloyd et al., 2019), PIU is more likely to occur under a physically constrained environment. The prevalence of PIU students in the current study was $30.6 \%$, which is statistically significantly higher than some previous studies' results (Gupta, Khan, Rajoura, \& Srivastava, 2018; Wang et al., 2020; Young et al., 2012). Compared to those with a weak internal LOC, students with a strong internal LOC suffered less from the sudden change in their living and learning conditions and held strong beliefs about controlling the social rewards in the offline world based on their effort (Rotter, 1966). Thus, an internal LOC is a typical trait that can be harnessed to cope with external shock and reduce the risk of PIU among residential college students.

Relationships between objective peer effects and PIU reveal significant patterns. Our results differ from previous studies focused on adolescents, which consistently show a positive relationship between objective peer effects and deviant behaviors (Haynie, 2002; Lorant \& Tranmer, 2019; Rulison et al., 2014). In our study, the objective peer effects-indegree, betweenness, and percentage of PIU peers-were not direct risk factors for the adoption of problematic behaviors among college students, a more mature group than adolescents. This could be explained by Moffitt's (1993) maturity gap hypothesis: To obtain desirable resources, the deviant/problematic behavior is more likely to be diffused by peer effects during one's adolescence. Once biological and social maturity are balanced, the transmissibility of deviant/problematic behavior is suppressed. In our sample, college students represent typical emerging adults, who are usually aware of rewards and punishments regarding personal behaviors. Thus, the advantage of diffusing PIU in their network is not necessarily associated with advantaged network positions.

The moderating roles of PIU peers' percentage provides significant evidence on the mechanisms of PIU's development. First, the percentage of PIU moderated the relationship between an internal LOC and PIU. Despite an internal LOC being PIU's protective factor, this effect was diluted when one was exposed to a high percentage of PIU in a peer environment. Second, the role of indegree in influencing PIU was conditionally moderated by the percentage of PIU peers. Indegree served as a protective factor of PIU when one had few PIU friends. However, if the percentage of PIU peers was high, students with high indegree had a high probability of PIU. These moderation results were similar to Haynie's (2001) findings. Even individuals' maturity gap was closed, as the peer effects from deviant/problematic behavior when adopting friends still negatively impacted personal behavior. Lastly, the result of the interaction item on the percentage of PIU peers and betweenness revealed that the protective efficacy of betweenness became activated when individuals had one or more PIU friends.

These results revealed that indegree and betweenness perform different roles among college students. High indegree students were usually viewed as role models and are thus, more likely to interact with other sub-community members. Therefore, high indegree students were more likely to be PIU foregoers when exposed to deviant subcommunities (e.g. PIU sub-networks) during the lockdown. However, they usually have a lower probability of PIU when exposed to non-deviant sub-communities. On the other hand, high betweenness students in this study displayed higher resilience to stressful events and had a lower probability of PIU. This result was consistent with Baron and Tindall's (1993) findings indicating that high betweenness individuals usually highly identify with the missions and social values of the network, and are thus, likely to be influenced by deviant/problematic peers.

This study also suggests several practical implications for university management during the COVID-19 pandemic. First, students with weak internal loci of control are vulnerable during lockdown due to university's closed-management strategies. Thus, counseling programs should pay more attention to this population, providing them with timely psychological support. Second, the attribute of students' real-life, offline world (e.g., the position of one's network) considerably impacts PIU. Since pandemic-related measures request that individuals substitute offline activities with online ones, 
student affair officers at universities should launch activities that integrate online activities with offline campus events to reduce students' virtual content consumption duration.

This study has several limitations. First, no causal inference can be made due to the study's cross-sectional design, and the study cannot differentiate between PIU's contagious and selection mechanisms. Given the relatively short-term of universities' closed-management measures (two months in the current study), it is difficult to observe the development of friend network. Future studies should incorporate longitudinal designs to close this gap. Second, self-reported measurements, especially IAT, may influence potential recall and same-source bias. Therefore, future studies should adopt objective measures (e.g. screen time records, internet browsing traces) to overcome these biases. Third, an internal LOC was measured by a one-item scale (Inglehart et al., 2014), which may not be a psychometrically reliable instrument. Further studies may adopt Rotter's (1966) two-dimension scale or Levenson's (1973) threedimension measurement to shed further insight on this effect. Fourth, the PIU prevalence rate reached as high as about $30 \%$ in this study. PIU may indeed be severe in specific circumstances. However, this prevalence rate may have been overestimated by the IAT scale (Griffiths, 2000). Lastly, this study's sample was recruited from one department of a university. Therefore, findings should be generalized cautiously to a broader population.

\section{CONCLUSIONS}

The current study reveals a high prevalence of PIU among residential college students during the COVID-19 lockdown, suggesting that the lockdown policy has inevitably impacted their social life. Amidst sudden social and personal development, they are vulnerable to PIU during such a stressful event. Future intervention programs during lockdown should pay attention to those with weak internal loci of control and consider network structure attributions.

Funding: This study was supported by Major Project of The National Social Science Fund of China (Grant No. 19ZDA324) and Huaqiao University (Grant No. 60550Y190420002)

Authors' contribution: YX wrote the first draft of the study, YF revised the first draft, THL took the investigation, ZM made the conceptualization and design. All authors approved the final manuscript.

Conflict of interest: The authors declare no conflict of interest.

\section{REFERENCES}

Alfano, V., \& Ercolano, S. (2020). The efficacy of lockdown against COVID-19: A cross-country panel analysis. Applied Health
Economics and Health Policy, 18(4), 509-517. https://doi.org/ 10.1007/s40258-020-00596-3.

Anderson, E. L., Steen, E., \& Stavropoulos, V. (2017). Internet use and problematic internet use: A systematic review of longitudinal research trends in adolescence and emergent adulthood. In International Journal of Adolescence and Youth, 22(4), 430-454, Routledge. https://doi.org/10.1080/02673843.2016.1227716.

Arnett, J. J., Žukauskiene, R., \& Sugimura, K. (2014). The new life stage of emerging adulthood at ages 18-29 years: Implications for mental health. The Lancet Psychiatry, 1(7), 569-576. https:// doi.org/10.1016/S2215-0366(14)00080-7.

Baron, S. W., \& Tindall, D. B. (1993). Network structure and delinquent attitudes within a juvenile gang. Social Networks, 15(3), 255-273. https://doi.org/10.1016/0378-8733(93)90008-9.

Blanchard, A. L., \& Henle, C. A. (2008). Correlates of different forms of cyberloafing: The role of norms and external locus of control. Computers in Human Behavior, 24(3), 1067-1084. https://doi.org/10.1016/j.chb.2007.03.008.

Burt, R. S. (2015). Reinforced structural holes. Social Networks, 43, 149-161. https://doi.org/10.1016/j.socnet.2015.04.008.

Centola, D., \& Macy, M. (2007). Complex contagions and the weakness of long ties. American Journal of Sociology, 113(3), 702-734. https://doi.org/10.1086/521848.

Chak, K., \& Leung, L. (2004). Shyness and locus of control as predictors of internet addiction and internet use. CyberPsychology and Behavior, 7(5), 559-570. https://doi.org/10.1089/ 1094931042403073.

Choi, H. J., Hecht, M., \& Smith, R. A. (2017). Investigating the potential impact of social talk on prevention through social networks: The relationships between social talk and refusal selfefficacy and norms. Prevention Science, 18(4), 459-468. https:// doi.org/10.1007/s11121-017-0764-6.

Daw, J., Margolis, R., \& Verdery, A. M. (2015). Siblings, friends, course-mates, club-mates: How adolescent health behavior homophily varies by race, class, gender, and health status. Social Science and Medicine, 125, 32-39. https://doi.org/10.1016/j. socscimed.2014.02.047.

Dawson, J. F. (2014). Moderation in management research: What, why, when, and how. Journal of Business and Psychology, 29(1), 1-19. https://doi.org/10.1007/s10869-013-9308-7.

Di Domenico, L., Pullano, G., Sabbatini, C. E., Boëlle, P. Y., \& Colizza, V. (2020). Impact of lockdown on COVID-19 epidemic in Île-de-France and possible exit strategies. BMC Medicine, 18(1), 1-13. https://doi.org/10.1186/s12916-020-01698-4.

Dong, H., Yang, F., Lu, X., \& Hao, W. (2020). Internet addiction and related psychological factors among children and adolescents in China during the Coronavirus disease 2019 (COVID19) epidemic. Frontiers in Psychiatry, 11(September), 1-9. https://doi.org/10.3389/fpsyt.2020.00751.

Elmer, T., Mepham, K., \& Stadtfeld, C. (2020). Students under lockdown: Comparisons of students' social networks and mental health before and during the COVID-19 crisis in Switzerland. PloS One, 15(7 July), 1-22. https://doi.org/10.1371/ journal.pone.0236337.

Faris, R., \& Felmlee, D. (2011). Status struggles: Network centrality and gender segregation in same- and cross-gender aggression. American Sociological Review, 76(1), 48-73. https://doi.org/10. 1177/0003122410396196. 
Faris, R., \& Felmlee, D. (2014). Casualties of social combat: School networks of peer victimization and their consequences. American Sociological Review, 79(2), 228-257. https://doi.org/10. 1177/0003122414524573.

Faris, R., Felmlee, D., \& McMillan, C. (2020). With friends like these: Aggression from amity and equivalence. American Journal of Sociology, 126(3), 673-713. https://doi.org/10.1086/712972.

Flaudias, V., Iceta, S., Zerhouni, O., Rodgers, R. F., Billieux, J., Llorca, P. M., et al. (2020). COVID-19 pandemic lockdown and problematic eating behaviors in a student population. Journal of Behavioral Addictions, 9(3), 826-835. https://doi.org/10.1556/ 2006.2020.00053.

Foshee, V. A., Benefield, T. S., Mcnaughton Reyes, H. L., Eastman, M., Vivolo-Kantor, A. M., Basile, K. C., et al. (2016). Examining explanations for the link between bullying perpetration and physical dating violence perpetration: Do they vary by bullying victimization? Aggressive Behavior, 42(1), 66-81. https://doi. org/10.1002/ab.21606.

Foshee, V. A., Benefield, T. S., Reyes, H. L. M. N., Ennett, S. T., Faris, R., Chang, L. Y., et al. (2013). The peer context and the development of the perpetration of adolescent dating violence. Journal of Youth and Adolescence, 42(4), 471-486. https://doi. org/10.1007/s10964-013-9915-7.

Fruchterman, T. M. J., \& Reingold, E. M. (1991). Graph drawing by force-directed placement. Software: Practice and Experience, 21(11), 1129-1164. https://doi.org/10.1002/spe.4380211102.

Griffiths, M. (2000). Internet addiction - time to be taken seriously? Addiction Research, 8(5), 413-418. https://doi.org/10.3109/ 16066350009005587.

Gupta, A., Khan, A., Rajoura, O., \& Srivastava, S. (2018). Internet addiction and its mental health correlates among undergraduate college students of a university in North India. Journal of Family Medicine and Primary Care, 7(4), 721. https://doi.org/ 10.4103/jfmpc.jfmpc_266_17.

Hair, M., Renaud, K. V., \& Ramsay, J. (2007). The influence of selfesteem and locus of control on perceived email-related stress. Computers in Human Behavior, 23(6), 2791-2803. https://doi. org/10.1016/j.chb.2006.05.005.

Haynie, D. L. (2001). Delinquent peers revisited: Does network structure matter? American Journal of Sociology, 10(4), 10131057. https://doi.org/10.1086/320298.

Haynie, D. L. (2002). Friendship networks and delinquency: The relative nature of peer delinquency. Journal of Quantitative Criminology, 18(2), 99-134. https://doi.org/10.1023/A: 1015227414929.

Helmbrecht, B., \& Ayars, C. (2021). Predictors of stress in firstgeneration college students. Journal of Student Affairs Research and Practice, 1-13. https://doi.org/10.1080/19496591.2020. 1853552.

Hirschi, T. (1969). Causes of deliquency. University of California Press.

Hoeben, E. M., Meldrum, R. C., Walker, D., \& Young, J. T. N. (2016). The role of peer delinquency and unstructured socializing in explaining delinquency and substance use: A state-ofthe-art review. Journal of Criminal Justice, 47, 108-122. https:// doi.org/10.1016/j.jcrimjus.2016.08.001.

Huang, R., \& Sun, X. (2014). Weibo network, information diffusion and implications for collective action in China. Information
Communication and Society, 17(1), 86-104. https://doi.org/10. 1080/1369118X.2013.853817.

Inglehart, R., Haerpfer, C., Moreno, A., Welzel, C., Kizilova, K., Diez-Medrano, J., et al. (2014). World values survey: Round sixcountry-pooled datafile version. Madrid: JD Systems Institute. http://www.worldvaluessurvey.org/WVSDocumentationWV6. jsp.

Kawachi, I., \& Berkman, L. (2014). Social capital, social cohesion, and health. In Berkman L. \& Kawachi I. (Eds.), Social epidemilogy (2nd ed., pp. 290-319). Oxford University Press.

Ko, C. H., \& Yen, J. Y. (2020). Impact of COVID-19 on gaming disorder: Monitoring and prevention. Journal of Behavioral Addictions, 9(2), 187-189. https://doi.org/10.1556/2006.2020.00040.

Koo, D. M. (2009). The moderating role of locus of control on the links between experiential motives and intention to play online games. Computers in Human Behavior, 25(2), 466-474. https:// doi.org/10.1016/j.chb.2008.10.010.

Kurtović, A., Vuković, I., \& Gajić, M. (2018). The effect of locus of control on university students' mental health: Possible mediation through self-esteem and coping. The Journal of Psychology: Interdisciplinary and Applied, 152(6), 341-357. https://doi.org/ 10.1080/00223980.2018.1463962.

Landau, R. (1995). Locus of control and socioeconomic status: Does internal locus of control reflect real resources and opportunities or personal coping abilities? Social Science \& Medicine, 41(11), 1499-1505. https://doi.org/10.1016/0277-9536(95)00020-8.

Lau, H., Khosrawipour, V., Kocbach, P., Mikolajczyk, A., Schubert, J., Bania, J., et al. (2020). The positive impact of lockdown in Wuhan on containing the COVID-19 outbreak in China. Journal of Travel Medicine, 27(3), 1-7. https://doi.org/10.1093/ $\mathrm{jtm} / \mathrm{taaa} 037$.

Lee, D., \& Lee, B. (2020). The role of multilayered peer groups in adolescent depression: A distributional approach. American Journal of Sociology, 125(6), 1513-1558. https://doi.org/10. 1086/709425.

Levenson, H. (1973). Perceived parental antecedents of internal powerful others, and chance locus of control orientations. Developmental Psychology, 9(2), 260-265. https://doi.org/10. 1037/h0035127.

Li, D., Li, X., Wang, Y., Zhao, L., Bao, Z., \& Wen, F. (2013). School connectedness and problematic internet use in adolescents: A moderated mediation model of deviant peer affiliation and selfcontrol. Journal of Abnormal Child Psychology, 41(8), 12311242. https://doi.org/10.1007/s10802-013-9761-9.

Lloyd, J., Frost, S., Kuliesius, I., \& Jones, C. (2019). Locus of control and involvement in videogaming. New Media and Society, 21(7), 1613-1635. https://doi.org/10.1177/1461444819828308.

Lorant, V., \& Tranmer, M. (2019). Peer, school, and country variations in adolescents' health behaviour: A multilevel analysis of binary response variables in six European cities. Social Networks, 59(June), 31-40. https://doi.org/10.1016/j.socnet.2019.05.004.

Mestre-Bach, G., Blycker, G. R., \& Potenza, M. N. (2020). Pornography use in the setting of the COVID-19 pandemic. Journal of Behavioral Addictions, 9(2), 181-183. https://doi.org/ 10.1556/2006.2020.00015.

Moffitt, T. E. (1993). Adolescence-limited and life-course-persistent antisocial behavior: A developmental taxonomy. Psychological Review, 100(4), 674-701. https://doi.org/10.1037/0033-295X.100.4.674. 
Odriozola-González, P., Planchuelo-Gómez, Á., Jesús Irurtia, M., \& Luis-Garcia, R. de. (2020). Psychological effects of the COVID19 outbreak and lockdown among students. Psychiatry Research, 290(January), 113180.

Pals, H., Love, T. P., Hannibal, B., \& Waren, W. (2016). The consequences of school environment and locus of control on adulthood deviant behavior. Deviant Behavior, 37(9), 10031022. https://doi.org/10.1080/01639625.2016.1167430.

Pfefferbaum, B., \& North, C. S. (2020). Mental health and the Covid-19 pandemic. The New England Journal of Medicine, 383(6), 510-512. https://doi.org/10.1056/NEJMp2008017.

Rotsztein, B. (2003). Problem Internet use and locus of control among college student: Preliminary findings. In 35th Annual Conference of the New England Educational Research Organization, 1-13.

Rotter, J. B. (1966). Generalized expectancies for internal versus external control of reinforcement. Psychological Monographs: General and Applied, 80(1), 1-28. https://doi.org/10.1037/ h0092976.

Rulison, K. L., Kreager, D. A., \& Wayne Osgood, D. (2014). Delinquency and peer acceptance in adolescence: A within-person test of Moffitt's hypotheses. Developmental Psychology, 50(11), 2437-2448. https://doi.org/10.1037/a0037966.

Shorrocks, A. F. (1982). Inequality decomposition by factor components. Econometrica, 50(1), 193. https://doi.org/10.2307/1912537.

Sinclair, D. L., Vanderplasschen, W., Savahl, S., Florence, M., Best, D., \& Sussman, S. (2020). Substitute addictions in the context of the COVID-19 pandemic. Journal of Behavioral Addictions, 15. https://doi.org/10.1556/2006.2020.00091.

Siste, K., Hanafi, E., Sen, L. T., Christian, H., Adrian, Siswidiani, L. P., Murtani, B. J., et al. (2020). The impact of physical distancing and associated factors towards internet addiction among adults in Indonesia during COVID-19 pandemic: A nationwide web- based study. Frontiers in Psychiatry, 11(September), 1-11. https://doi.org/10.3389/fpsyt.2020.580977.

Soh, P. C. H., Chew, K. W., Koay, K. Y., \& Ang, P. H. (2018). Parents vs peers' influence on teenagers' Internet addiction and risky online activities. Telematics and Informatics, 35(1), 225236. https://doi.org/10.1016/j.tele.2017.11.003.

Spector, P. E., Cooper, C. L., Sanchez, J. I., O’Driscoll, M., Sparks, K., Bernin, P., et al. (2001). Do national levels of individualism and internal locus of control relate to wellbeing: An ecological level international study. Journal of Organizational Behavior, 22(8), 815-832. https://doi.org/10. 1002/job.118.

Sullivan, S. A., Thompson, A., Kounali, D., Lewis, G., \& Zammit, S. (2017). The longitudinal association between external locus of control, social cognition and adolescent psychopathology. Social Psychiatry and Psychiatric Epidemiology, 52(6), 643-655. https://doi.org/10.1007/s00127-017-1359-Z.

Wang, Q., Liu, Y., Wang, B., An, Y., Wang, H., Zhang, Y., et al. (2020). Problematic internet use and subjective sleep quality among college students in China: Results from a pilot study. Journal of American College Health, 1-9. https://doi.org/10. 1080/07448481.2020.1756831.

Xia, Y., \& Ma, Z. (2020). Social integration, perceived stress, locus of control, and psychological wellbeing among Chinese emerging adult migrants: A conditional process analysis. Journal of Affective Disorders, 267(November), 9-16. https://doi. org/10.1016/j.jad.2020.02.016.

Young, K. S. (1998). Internet addiction: The emergence of a new clinical disorder. CyberPsychology and Behavior, 1(3), 237-244. https://doi.org/10.1089/cpb.1998.1.237.

Young, K. S., Yue, X. D., \& Ying, L. (2012). Prevalence estimates and etiologic models of internet addiction. In Internet addiction. https://doi.org/10.1002/9781118013991.ch1. 